\title{
Article
}

\section{The challenges that challenge: engaging with agile practitioners' concerns}

Gregory, Peggy, Barroca, L, Sharp, H, Deshpande, A and Taylor, KJ Available at http://clok.uclan.ac.uk/14220/

Gregory, Peggy ORCID: 0000-0001-7891-6666, Barroca, L, Sharp, H, Deshpande, A and Taylor, KJ ORCID: 0000-0003-4840-9991 (2016) The challenges that challenge: engaging with agile practitioners' concerns. Information and Software Technology, 77 . pp. 92-104. ISSN 0950-5849

It is advisable to refer to the publisher's version if you intend to cite from the work. http://dx.doi.org/10.1016/j.infsof.2016.04.006

For more information about UCLan's research in this area go to http://www.uclan.ac.uk/researchgroups/ and search for < name of research Group>.

For information about Research generally at UCLan please go to http://www.uclan.ac.uk/research/

All outputs in CLoK are protected by Intellectual Property Rights law, including Copyright law. Copyright, IPR and Moral Rights for the works on this site are retained by the individual authors and/or other copyright owners. Terms and conditions for use of this material are defined in the policies page.

\section{CLoK}

Central Lancashire online Knowledge www.clok.uclan.ac.uk

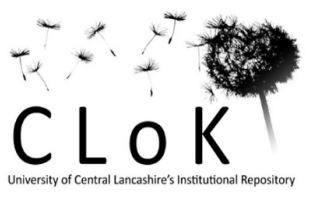




\section{The Challenges That Challenge: Engaging With Agile Practitioners' Concerns}

Peggy Gregorya ${ }^{*}$, Leonor Barrocab ${ }^{b}$, Helen Sharp ${ }^{b}$, Advait Deshpandeb, Katie Taylora

a University of Central Lancashire, Preston PR1 2HE, UK

b The Open University, Walton Hall, Milton Keynes MK7 6AA, UK

ajgregory, kjtaylor@uclan.ac.uk, leonor.barroca, helen.sharp, advait.deshpande@open.ac.uk

${ }^{*}$ Corresponding author

\section{Abstract}

Context: There continues to be concern that research is not addressing the challenges that practice faces. For the benefit of academia and industry, researchers need to be aware of practitioners' challenges and their context so that relevant and applicable research is undertaken.

Objective: This paper investigates two research questions: what challenges do agile practitioners face? and, how do practitioner challenges manifest themselves in an organisational setting? It aims to map the practitioner challenge landscape, explore challenge characteristics, compare findings with previous literature and identify implications for research that is relevant to practice.

Method: A combination of methods was used: elicitation of practitioner challenges collected using a Challenge Wall at a series of practitioner events; organisational Case Study using interviews, document analysis and observation; and online Survey. Findings were then compared to previous publications.

Results: Challenges collected from the Challenge Wall were grouped under 27 subthemes and seven themes: Claims and Limitations, Organisation, Sustainability, Culture, Teams, Scale, and Value. Investigating one challenge in the Case Study uncovered a set of new challenges, which were interrelated. Over $50 \%$ of survey respondents experienced challenges highlighted in the Case Study.

Conclusion: The landscape of agile practitioner challenges is complex and intertwined. Some challenges, such as doing agile in a non-agile environment, are multi-dimensional, affect many aspects of practice, and may be experienced simultaneously as business, organisational, social and adaptation problems. Some challenges, such as understanding cultural change or measuring agile value, persist and are hard to address, while others, such as adoption, change focus over time. Some challenges, such as governance and contracts, are under-researched, while others, such as business and IT transformation, have been researched but findings have not had the expected impact. Researchers wishing to address practitioner challenges need to treat them in context rather than in isolation and improve knowledge transfer.

\section{Keywords}

Agile Methods, Agile Software Development, Challenges, Evidence-based Software Engineering, DSDM 


\section{Introduction}

Successfully adopting and using agile approaches within an organisation is challenging. As agile approaches mature and their use becomes more widespread [1], the nature of the challenges that practitioners and organisations face is changing. New challenges are emerging and the focus of existing challenges is shifting, reflecting the current state of practice. Some challenging activities, for example setting up a Scrum team, have been the subject of research and are now better understood [2, 3]. There is a growing body of research literature, experience reports, books and guidelines providing suggestions for those seeking help. Even so, some known challenges still pose problems in practice. Additionally, new challenges are emerging as organisations push the boundaries of existing techniques and try new approaches or move into unknown territory.

Agility is a very broadly understood concept that is difficult to define clearly [4]. The Agile Manifesto declaration and principles remain the de facto delineation of agile [5] to which authors frequently refer. In practice, discussion often focuses on specific methods, but even then there are many options for organisations to choose from. A recent survey [1] confirms that a wide variety of methods are used in industry; the most common being Scrum, followed by: 'home-grown' approaches, Extreme Programming (XP), Scrum/XP Hybrid, Lean Software Development, Feature Driven Development and Dynamic Systems Development Method (DSDM). In this paper the term 'agile practitioners' is defined widely to mean anyone working in an organisation who is involved in either making decisions about agile or using an agile approach. This covers a wide range of roles from executive directors to software developers. We have not imposed our own definition of agile on this work, but follow Lyytinen and Rose [6], in relying on research participants to use their own definitions of agility.

If academic research is to be relevant to practice, researchers need to keep abreast of practitioner challenges, have a grounded understanding of them, and be able to tackle the changing landscape of practitioner challenges as it evolves. This paper seeks to address two research questions:

RQ1: What challenges do agile practitioners face?

RQ2: How do practitioner challenges manifest themselves in an organisational setting? The first research question explores the landscape of practitioners' agile challenges. The aim is to capture an overview of challenges - the breadth rather than the depth. This question is addressed by the Challenge Wall study described in section 3.1. The second research question explores challenges within organisations and aims to uncover rich detail about those challenges. This is addressed by the Case Study described in section 3.2 and the Survey described in section 3.3. 
In answering these research questions we also compare the current landscape with previous reports of practitioner challenges, consider what challenges have been tackled in the research literature, and discuss the nature of agile practitioner challenges.

This paper is an extended version of Gregory et al. [7], which presented a snapshot of challenges gathered from practitioners using a Challenge Wall and discussed how the challenge landscape has changed. This extended paper continues and deepens that discussion by bringing in empirical data from an organisational Case Study and a Survey and exploring challenge characteristics.

In this paper, Section 2 presents previous literature on the need for industrial engagement with academic research and previous investigations of practitioner challenges. Section 3 has three sections. The first introduces the Challenge Wall and presents the results of a thematic analysis of challenges collected during 2013 and 2014; the second presents a Case Study and reports a detailed investigation into practitioner challenges in one organisation; and the third presents results from an online Survey undertaken to expand insights from the Case Study. Section 4 returns to the research questions and discusses the implications of the findings and Section 5 presents conclusions.

\section{Related Work}

A series of papers has charted the progress of agile research since its early days. In 2003 Abrahamson et al found 'a jungle of emerged software development methods', and a lack of empirical evidence to support ideas [8]. In 2008, Dingsøyr et al [9], stated that the primary challenge for agile research was to combine academic rigour with industrial relevance, suggesting that researchers could use research methods such as action research as a way to increase relevance and impact. In a systematic review in the same year, Dybå and Dingsøyr concluded that there was a need for more empirical research, and suggested that researchers should aim to understand the drivers of agile adoption as well as its effects [10]. The call for more research continued in 2009 by Abrahamson et al. [11], who also identified a need for more rigour and industrial studies, as well as highlighting a lack of clarity about what was meant by agility. More recently the research landscape has changed. Both Dingsøyr et al in 2012 [12] and Chuang et al in 2014 [13] have reported an increase in published research, indicating a maturing field.

Research in agile has addressed a number of specific topic areas highlighted in several systematic literature reviews; these include reviews of the state of research, synthesis of research themes and identification of challenges. For example, a 2011 review of agile global software engineering literature [14] concluded that research was increasing but there was a predominance of industrial experience reports which report on modifications to practice based on contextual factors. A 2014 review of 
communication in agile global software development identified seven research themes, and reported that about half of the chosen papers were experience reports [15]. The predominance of industrial experience reports in the agile literature has been noted by a number of authors [14-16]. Experience reports are extremely useful as they tell a contextualised story about an organisation, and in doing so describe practice, suggest practical techniques, and provide guidelines. However, there are limitations to this type of literature. They rarely use theory or try to develop a deeper understanding of the phenomena and situations they report on. They also usually tell positive stories of problems solved rather than describing persistent difficulties, worsening situations or failures. As a result they provide snapshots of successful practice, but almost certainly do not represent the state-of-the-practice. Indeed, few papers describe major unresolved problems or failures, resulting in a general publication bias towards only reporting success. Since many lessons are learnt in response to mistakes and failures, this bias, although unsurprising, is not helpful. This problem is not specific to the agile area, and has been noted in other disciplines [17].

Industrial experience reports have limitations but so does academic research, in particular, guaranteeing its relevance to practice. To address this limitation, other approaches have been used to identify research questions. For example, during a panel discussion at XP2010 (http://xp2010.org/) practitioners said researchers did not always address questions they wanted answering. During the rest of the conference delegates were asked to suggest and vote on topics that should be researched, in order to create a prioritised list of 'burning issues' for the agile research community [18] (see Table 5). During an XP2013 workshop Dingsøyr and Moe elicited and ranked eight research challenge topics for large-scale agile software development [19] from a mixture of practitioners and academics. Topics were, in ranked order, Inter-team coordination; Large project organisation/portfolio management; Release planning and architecture; Scaling agile practices; Customer collaboration; Large-scale agile transformation; Knowledge sharing and improvement and Agile contracts. Taking this approach to identifying research questions is a more direct way of ensuring research relevance, but how relevant the challenges are to practice depends on who is suggesting them.

The work presented in this paper explores challenges with agile development. Several attempts have been made to categorise challenges faced in the application of agile. Gandomani et al. [20] identified four categories of challenges faced by organisations when migrating to agile: organisation and management; people; process; and tools related challenges. This classification is based solely on existing literature. Using grounded theory, van Waardenburg and van Vliet [21] investigated the challenges caused by the co-existence of agile methods and plan-driven development, and discussed mitigation strategies for those challenges. This work is based on 21 interviews with agile practitioners from two large enterprises in the Netherlands. They organised the challenges under two categories: 
'Increased landscape complexity' and 'Lack of business involvement'. The paper exposes consequences of the former category as 'Problems with communication', 'Dependent definition of done', and 'Difficulties to create change'. The consequences of the latter category are 'Problems with requirements gathering', 'Slow reaction to change', 'Problems with requirements prioritisation' and 'Limited feedback from the business'. For both challenge categories, mitigation strategies were proposed that focused on communication between the agile and traditional part of the organisation, and the communication timing.

Conboy et al [22] identified nine themes for challenges experienced by 17 large multinational organisations using agile methods. The research focused on challenges encountered by people involved in the agile development process. The themes were: developer fear as a result of the transparency of skill deficiencies; the need for developers to be "master of all trades"; dependency on social skills; deficiency of developers' business knowledge; the need to understand and learn values and principles of agile, not just the practices; lack of developer motivation to use agile methods; implications of devolved decision-making; the need for agile compliant performance evaluation; and absence of specific recruitment policies and absence of trained IT graduates for agile.

These related works are discussed further in section 4.1 and 4.3 in the light of our findings.

\section{Investigating Practitioner Challenges}

This section presents three studies undertaken to investigate agile practitioners' challenges. Section 3.1 reports the Challenge Wall study, undertaken to answer RQ1, what challenges do practitioners face? Section 3.2 reports a Case Study investigation of challenges experienced by the London office of a large financial organisation, undertaken to answer RQ2, how do practitioner challenges manifest themselves in an organisational setting? Section 3.3 reports an online Survey developed to investigate further the Case Study findings, and to further explore RQ2.

\subsection{Challenge Wall}

This section reports how a Challenge Wall (Figure 1) was used to collect challenges from agile practitioners and presents a thematic analysis of the findings.

\subsubsection{Approach}

A Challenge Wall was deployed at five Agile Conferences and events between October 2013 and October 2014: the Agile Business Conference, London, October 2013 (www.agileconference.org); DSDM Members Day, Manchester, November 2013 (www.dsdm.org); XP, Rome, May 2014 (www.xp2014.org); AgileNorth, Preston, June 2014 (www.agilenorth.org); and the Agile Business Conference, London, 
October 2014 (www.agileconference.org). Attendees were mostly agile practitioners and business representatives, except for the XP Conference in 2014 that was attended by a mixture of practitioners and academics. Four of the events were based in the UK; the XP Conference was based in Rome. Practitioner and business attendees represented a range of organisational roles. The job roles of attendees at the 2013 and 2014 ABC Conferences and the DSDM Manchester Members Day 2014, the only events about which we had access to such data, are shown in Figure 2.

Figure 1: The Challenge Wall at $\mathrm{ABC} 2013$

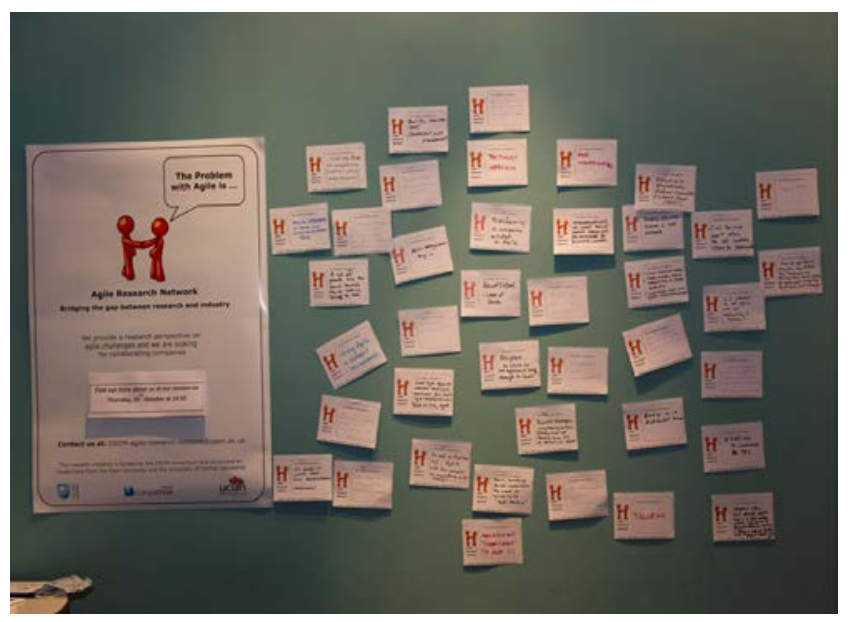

The Challenge Wall was set up by positioning a poster in a visible place in the conference or event venue and providing a stack of pens and small blank challenge cards. Delegates were encouraged to fill out the cards anonymously (Figure 3), and these were then attached to the wall next to the poster for others to read. Delegates wrote one challenge per card, and could fill in as many cards as they wished. The Challenge Wall gradually grew throughout the event, and became a trigger for discussions between delegates and the authors about the nature and context of the challenges identified.

Figure 2: Job roles for attendees at ABC 2013, ABC 2014 and DSDM Manchester Members Day 2015

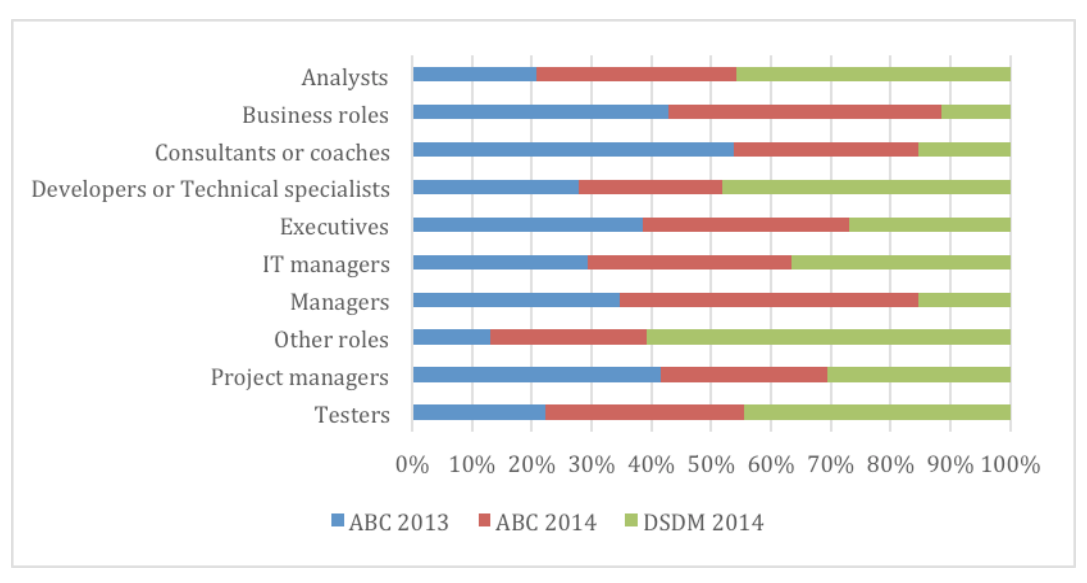

A thematic analysis approach was used for data analysis [23]. Three researchers each completed an independent thematic analysis of the challenges. These analyses were done separately, with no initial list of themes. Each researcher used their own individual approach. Two researchers worked by 
identifying codes first which they then grouped into subthemes, the third focused solely on identifying subthemes. The two different researchers reviewed the independent lists. They verbally clarified the meaning of the descriptors used by the other researchers, and created a merged list of subthemes. Merging started by looking at subtheme names and their associated challenges, and went on to identify high-level themes, which were used as grouping mechanisms for the more detailed subthemes.

Discussion focussed on whether to merge or split subthemes, finding appropriate names for subthemes, and identifying broad themes at the right level of granularity. For example, 'Culture' and 'Changing Mindsets/Culture' had been identified as subthemes by two of the independent analysts, but a distinction between organisational culture and national culture had not been made, so the reviewers created these as themes. They regrouped the data into nine themes and 27 subthemes. This set of themes was revised again through discussions between all researchers using Skype calls and emails, and the final set of seven themes and 27 subthemes was agreed. For example, through group discussion at this final stage it was decided that 'Organisational Culture' and 'National Culture' would be more appropriate as subthemes grouped under the broader theme of 'Culture'.

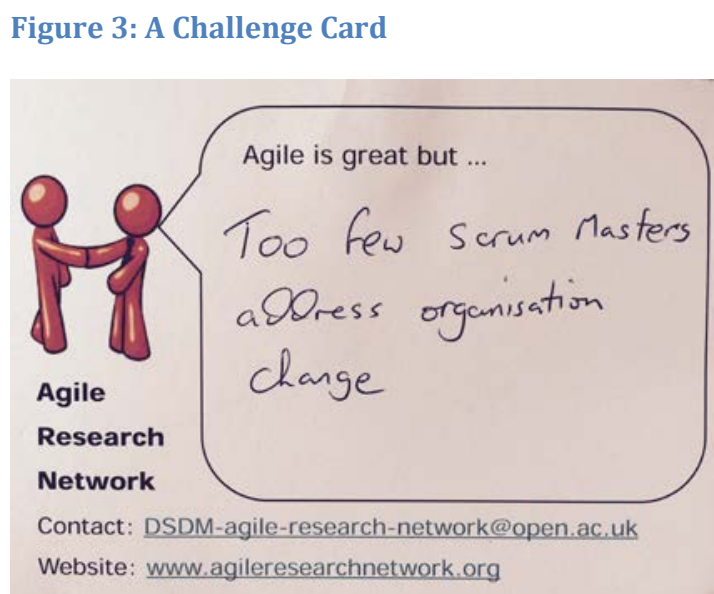

\subsubsection{Findings}

One hundred and ninety-four challenge cards were collected. Four were disregarded as inappropriate, because they were too difficult to understand. As a result of the thematic analysis described above the remaining 190 challenges determined the seven themes and 27 subthemes. Table 1 shows the themes and subthemes along with a description and an example challenge from each subtheme (excerpts of collected data are shown in italics). The table is ordered, largest first, by the number of challenges in the themes and subthemes, with the number of challenges in each group provided in brackets.

The thematic analysis of the Challenge Wall data highlighted two striking groups containing a high number of challenges: Claims and Limitations with 46 challenges (with the dominance of misconceptions, shortcomings, and hype), and Organisation with 44 challenges (with most highlighting business concerns, management buy-in and understanding, stakeholder commitment and engagement and a concern for agile within a non-agile environment). Culture, Teams and Sustainability were 
medium-sized groupings. Scaling and Value were the two smallest thematic groups. Value only contained seven challenge cards.

The challenge statements were diverse, as shown through the identification of 27 subthemes. Some challenge statements were brief, for example:

'Getting started'; and

'Tailoring'.

Others were lengthy, for example:

'Agile is just an umbrella term. So agile itself cannot be a problem. Adoption of agile approaches depends on understanding of the many techniques and ability or willingness to adopt an appropriate set of them. Flexibility or lack of it is the main problem'.

There was some repetition of content, for example four agile in a non-agile environment challenges were almost identical:

'Using agile in waterfall environments'; and

'It is agile but business still have a waterfall thinking'; and

'It is agile but most of the business are not'; and

'It is agile, rest of business isn' $t$ '.

Nevertheless there was a lot of variety. Challenges were expressed at different granularities, so some were quite high level, for example:

'Fully engaging the business'.

Others, however, were more detailed and at a lower level of granularity, for example:

'The system team having a different opinion of "done criteria" compared to a sub-team. The subteam counted "done" as working in the system, whereas the system-team only called each 'unit' as "done" prior to integration. We (the sub-team) felt this was naïve.

Some of the challenge statements covered many topics, and were therefore difficult to classify, for example a challenge such as:

"Changing from a command and control/mechanistic worldview to a future of autonomous, selfmanaged agents in a systemic organisation is too much if the system does not change itself including leaders".

This was classified under the subtheme Organisational culture in the Culture theme but could also have been classified under Commitment/engagement in the Organisation theme or Team practices in the Teams theme or Process improvement in the Sustainability theme. 
Table 1: Themes and subthemes identified from Challenge Wall cards, ordered by number of cards (in brackets)

\begin{tabular}{|c|c|c|c|c|}
\hline & Main Theme & Subthemes & Description of Subthemes & Example Challenge \\
\hline \multirow[t]{4}{*}{1} & \multirow[t]{4}{*}{$\begin{array}{l}\text { Claims and } \\
\text { Limitations (46) }\end{array}$} & $\begin{array}{l}\text { Misconceptions } \\
(23)\end{array}$ & $\begin{array}{l}\text { The multi-faceted aspects of agile are open to many } \\
\text { different interpretations }\end{array}$ & $\begin{array}{l}\text { "Shallow Adoption" where practices or processes are } \\
\text { followed mechanically without deep insight into } \\
\text { underlying values' }\end{array}$ \\
\hline & & \begin{tabular}{|l} 
Shortcomings \\
$(14)$
\end{tabular} & $\begin{array}{l}\text { Areas where information is sparse, limited or where } \\
\text { methods are used inappropriately }\end{array}$ & $\begin{array}{l}\text { 'Credibility in areas it has not traditionally been used (e.g. } \\
\text { public sector)' }\end{array}$ \\
\hline & & $\begin{array}{l}\text { Hype } \\
(8)\end{array}$ & Misleading or excessive claims about agile approaches & $\begin{array}{l}\text { 'It's become a buzzword and as such threatening its own } \\
\text { existence. It has to be implemented thoroughly and } \\
\text { comprehensively to get great outcomes' }\end{array}$ \\
\hline & & $\begin{array}{l}\text { Failure } \\
(1)\end{array}$ & Only limited evidence is available about failures & $\begin{array}{l}\text { 'Some believe it to be a "silver bullet" to their problems, } \\
\text { only to realise and not like that it just exposes their } \\
\text { existing issues' }\end{array}$ \\
\hline \multirow[t]{6}{*}{2} & \multirow[t]{6}{*}{$\begin{array}{l}\text { Organisation } \\
(44)\end{array}$} & $\begin{array}{l}\text { Business \& IT } \\
\text { transformation (11) }\end{array}$ & $\begin{array}{l}\text { Requires business and IT to collaborate to establish } \\
\text { agility throughout the entire value chain }\end{array}$ & $\begin{array}{l}\text { 'It's still seen as an IT methodology. It needs the business } \\
\text { teams to buy into it and join the party' }\end{array}$ \\
\hline & & $\begin{array}{l}\text { Management buy-in } \\
\& \text { understanding } \\
(10)\end{array}$ & $\begin{array}{l}\text { Traditional management may see agile as just another IT } \\
\text { method that can be implemented and structured to 'fit' } \\
\text { existing organisational norms }\end{array}$ & $\begin{array}{l}\text { 'Misconceptions of what 'agile' means. Perceived as quicker } \\
\text { by business owners' }\end{array}$ \\
\hline & & $\begin{array}{l}\text { Agile in a non-agile } \\
\text { environment } \\
(10)\end{array}$ & $\begin{array}{l}\text { Teams successfully adopt agile but operate in an } \\
\text { environment where wider organisational structures are } \\
\text { more traditional }\end{array}$ & 'IT is agile but most of the business are not' \\
\hline & & $\begin{array}{l}\text { Commitment/ } \\
\text { Engagement (7) }\end{array}$ & $\begin{array}{l}\text { Success can be challenged by lack of awareness or } \\
\text { commitment from other stakeholders }\end{array}$ & $\begin{array}{l}\text { 'It only works if all stakeholders get involved and support } \\
\text { the agile process' }\end{array}$ \\
\hline & & $\begin{array}{l}\text { Adoption } \\
(4)\end{array}$ & $\begin{array}{l}\text { Concerns around 'how to' introduce agile ways of } \\
\text { working either into teams or into the wider organisation }\end{array}$ & 'What is the holistic business case to move to agile?' \\
\hline & & $\begin{array}{l}\text { Fear } \\
(2)\end{array}$ & $\begin{array}{l}\text { Fear of change and the unknown as agile appears less } \\
\text { structured with people 'doing their own thing' whilst } \\
\text { using a whole new set of jargon }\end{array}$ & $\begin{array}{l}\text { 'Traditional practitioners may fear and resist the change } \\
\text { given control moves to the team (self- organising teams)' }\end{array}$ \\
\hline \multirow[t]{3}{*}{3} & \multirow[t]{3}{*}{$\begin{array}{l}\text { Culture } \\
(31)\end{array}$} & $\begin{array}{l}\text { Organisational } \\
\text { culture (13) }\end{array}$ & $\begin{array}{l}\text { The organisation requires a philosophical belief in people } \\
\text { over process }\end{array}$ & $\begin{array}{l}\text { 'Changing from a command and control/mechanistic } \\
\text { worldview to a future of autonomous, self-managed agents } \\
\text { in a systemic organisation is too much if the system does } \\
\text { not change itself-including leaders' }\end{array}$ \\
\hline & & $\begin{array}{l}\text { Changing mindsets } \\
\text { (7) }\end{array}$ & $\begin{array}{l}\text { Agile is more than a set of practices used by IT requiring } \\
\text { wide ranging change to work patterns }\end{array}$ & $\begin{array}{l}\text { 'It's a mind set not a methodology. Without a change in } \\
\text { mind set the result will not be met' }\end{array}$ \\
\hline & & National culture (5) & $\begin{array}{l}\text { Differences in national culture, particularly between East } \\
\text { and West, compound issues with organisational culture }\end{array}$ & $\begin{array}{l}\text { 'Is it possible to do agile with all nationalities and } \\
\text { cultures?' }\end{array}$ \\
\hline
\end{tabular}




\begin{tabular}{|c|c|c|c|c|}
\hline & \multirow[t]{2}{*}{ Culture contd. } & $\begin{array}{l}\text { Distributed teams } \\
(5)\end{array}$ & $\begin{array}{l}\text { Business realities are often contrary to the agile need for } \\
\text { co-located teams, with teams distributed across the UK, } \\
\text { Europe or worldwide }\end{array}$ & $\begin{array}{l}\text { 'It requires co-location in a digital world, where travel is } \\
\text { too expensive' }\end{array}$ \\
\hline & & Trust (1) & Providing a safe environment to develop and innovate & 'What is the cost for not investing in trust?' \\
\hline \multirow[t]{4}{*}{4} & \multirow[t]{4}{*}{$\begin{array}{l}\text { Teams } \\
(24)\end{array}$} & $\begin{array}{l}\text { Team practices } \\
\text { (11) }\end{array}$ & $\begin{array}{l}\text { Uncertainty and perhaps lack of training in specific } \\
\text { practices or techniques }\end{array}$ & $\begin{array}{l}\text { 'How to estimate/ better estimate the effort to support } \\
\text { planning?' }\end{array}$ \\
\hline & & $\begin{array}{l}\text { Leadership } \\
\text { (5) }\end{array}$ & $\begin{array}{l}\text { Traditional project management approaches of } \\
\text { 'command and control' need to be replaced by a } \\
\text { facilitation style of leadership }\end{array}$ & 'That the manifesto lacks Leadership over Management' \\
\hline & & $\begin{array}{l}\text { Finding good people } \\
(4)\end{array}$ & $\begin{array}{l}\text { Agile requires skilled, self-directed and motivated team } \\
\text { players }\end{array}$ & $\begin{array}{l}\text { 'Getting the right people interested-decision makers and } \\
\text { users' }\end{array}$ \\
\hline & & \begin{tabular}{|l|} 
Individual \\
motivation (4)
\end{tabular} & $\begin{array}{l}\text { Agile philosophies are often at odds with organisational } \\
\text { reward structures that value individuals }\end{array}$ & 'It sometimes marginalises lonely problem solvers' \\
\hline 5 & \multirow[t]{4}{*}{$\begin{array}{l}\text { Sustainability } \\
(23)\end{array}$} & $\begin{array}{l}\text { Process } \\
\text { improvement (15) }\end{array}$ & $\begin{array}{l}\text { Once adopted, agile requires on-going change and } \\
\text { commitment in order to become sustainable and } \\
\text { embedded within teams and the organisation }\end{array}$ & $\begin{array}{l}\text { 'If it is codified it becomes "bureaucratic" and if not it is } \\
\text { too diverse to be taken seriously' }\end{array}$ \\
\hline & & $\begin{array}{l}\text { Documentation } \\
(4)\end{array}$ & $\begin{array}{l}\text { Tensions arise when management sees documentation as } \\
\text { a way to demonstrate control whilst developers focus on } \\
\text { code over documents }\end{array}$ & $\begin{array}{l}\text { 'That it has become an excuse not to do any documentation } \\
\text { or planning beyond the sprint and product backlog' }\end{array}$ \\
\hline & & $\begin{array}{l}\text { Contracts } \\
(3)\end{array}$ & $\begin{array}{l}\text { Standard contracts require detailed upfront } \\
\text { specifications that are contrary to the evolving approach } \\
\text { of agile }\end{array}$ & 'Some think they need a contract' \\
\hline & & $\begin{array}{l}\text { Knowledge sharing } \\
\text { (1) }\end{array}$ & $\begin{array}{l}\text { Needs a positive learning environment to motivate } \\
\text { individual commitment in order to establish effective } \\
\text { knowledge sharing }\end{array}$ & 'We innovate but we don't really share innovations' \\
\hline \multirow[t]{2}{*}{6} & \multirow[t]{2}{*}{$\begin{array}{l}\text { Scaling } \\
(15)\end{array}$} & \begin{tabular}{|l} 
Large projects \\
$(10)$
\end{tabular} & $\begin{array}{l}\text { Working at programme level where team practices need } \\
\text { to scale across multiple teams in large complex projects }\end{array}$ & $\begin{array}{l}\text { 'Agility in large projects effecting several applications, } \\
\text { platforms, techniques' }\end{array}$ \\
\hline & & $\begin{array}{l}\text { Governance } \\
\text { (5) }\end{array}$ & $\begin{array}{l}\text { Traditional mechanisms that ensure projects achieve } \\
\text { regulatory or legal compliance are often process driven } \\
\text { and bureaucratic }\end{array}$ & $\begin{array}{l}\text { 'Have not yet found any clear view on how the 'governance' } \\
\text { at Business Case level works or could work in relation to } \\
\text { outcomes, costs and benefits' }\end{array}$ \\
\hline \multirow[t]{2}{*}{7} & \multirow[t]{2}{*}{$\begin{array}{l}\text { Value } \\
(7)\end{array}$} & $\begin{array}{l}\text { Business value } \\
\text { (4) }\end{array}$ & $\begin{array}{l}\text { To counter criticism of waterfall approaches where } \\
\text { organisations tended to focus on process rather than } \\
\text { product, agile projects must demonstrate value }\end{array}$ & 'Ensuring that projected value is achieved' \\
\hline & & $\begin{array}{l}\text { Measurement } \\
(3)\end{array}$ & $\begin{array}{l}\text { Many organisation use wide ranging metrics but these } \\
\text { are not always appropriate or necessary to agile projects }\end{array}$ & $\begin{array}{l}\text { 'The lack of well formulated and defined measurement } \\
\text { practices' }\end{array}$ \\
\hline
\end{tabular}




\subsubsection{Reliability and Limitations}

We follow Lincoln and Guba [24] in using credibility, transferability, dependability, and confirmability to discuss the reliability and validity of qualitative research. Credibility assesses whether the study measures what is intended [25]. It involves adopting appropriate methods, developing familiarity with the research context and establishing that results are believable from the perspective of the research participants. Transferability refers to the applicability of study results to other situations [25]. It is addressed through accurate descriptions of the research context and assumptions brought to the research. Dependability assesses whether the same results would be achieved if the study were repeated. It is addressed by reporting detailed descriptions of the research process to enable future researchers to repeat the work [25]. Confirmability assesses whether findings reflect research participants' experiences not the preferences of the researchers, and is related to the issue of objectivity [25]. This is addressed through the corroboration of research analysis by more than one researcher and recognition of the study shortcomings. These terms are used below and also in the other Reliability and Limitations sections: 3.2.4 and 3.3.3.

Credibility, transferability and dependability of the Challenge Wall findings are enhanced by the detailed descriptions of the data collection approach and context provided in this section. Collecting data through face-to-face contact with respondents at several events enhances credibility as the researchers are able to confirm that challenges were a genuine expression of respondents' views. There were several limitations to the data collection approach. Few software developers or testers attend such events therefore their views were not well represented in the dataset. The data capture occurred at conferences, and as participants were outside their normal working environment it is possible that this influenced the challenges captured. The challenge cards were filled in anonymously so they could not be linked to job roles. The events at which data was collected were all 'pro-agile', and respondent sampling was potentially skewed by this context. The data set only provides an insight into challenges at a particular time in a continually evolving landscape of challenges.

Confirmability of the analysis was strengthened by the researchers using a process of first working independently, and then collaboratively, to develop an understanding of the data. There were some disagreements between the researchers about theming choices, resulting in the need for negotiated decisions. The credibility of the analysis was not checked with participants, as data was collected anonymously.

\subsection{Case Study}

The challenge cards presented in the previous section provide an overview of the landscape of practitioner challenges, but they cannot capture any detail or context. Investigating challenges in more 
depth requires a different approach that allows the context and detail to be accounted for. A case study is "an empirical method aimed at investigating contemporary phenomena in their context" [26], and hence is appropriate for this purpose. Specifically, as the aim is to investigate practitioner challenges in context, an exploratory case study approach was taken.

Following an email sent to the DSDM members' mailing list asking for companies facing agile challenges to get in touch with us, the research team were approached in March 2013 by the London-based Office of a large multinational organisation in the finance sector (whom we shall call BigBank). Initially, the challenge they were facing was presented as one of reporting from the agile teams in the London Office to the Head Office, which was based in a different country. Over the course of the case study, it became clear that there were many different challenges being faced by staff in different roles, and working with the London Office staff, the essence of the challenge became characterized as "Agile projects in a nonagile environment".

\subsubsection{Context}

About two years before the case study started, the London office of BigBank decided to adopt the Dynamic Systems Development Method (DSDM). DSDM is an end-to-end framework for agile project management and delivery, whose underlying philosophy is to align projects with strategic business goals and deliver early benefits. DSDM does not prescribe any specific engineering practices and so the teams adopted a Scrum-based approach working within timeboxes (the DSDM term for sprints) and using a Prioritised Requirements List (the DSDM term for a product backlog). The DSDM framework also provides guidance for Project Management Office (PMO) management. The PMO is a department, commonly found in large organisations, whose function is to facilitate IT project management across the whole organization by making strategic decisions about projects, programmes and portfolios and ensuring repeatable processes. By the time of the study the London office had adopted DSDM in its entirety, however, the use of DSDM was not mature.

Influential in the decision to adopt DSDM, was the fact that several projects had failed in recent years, which had left uncertainty in the relationship between the Head Office and the London office. This background exacerbated the challenge and brought it into sharp focus. BigBank chose DSDM because they were operating in a regulated environment, and they needed to ensure that the approach they chose provided structure and governance mechanisms as well as agile processes. The agile transition was supported by management, and was achieved by a mix of employee training and help from consultants. Agile culture was gradually embraced and software was being delivered in regular increments. However their projects were approved, budgeted and monitored by Head Office who continued to use a waterfall approach and had a hierarchical structure. 
It soon became apparent that the use of agile practices was starting to cause problems between the London office and the Head Office. Representatives from the Head Office appeared sceptical about the agile approach. They always wanted to know more detail and asked questions which seemed to the London office to be irrelevant, or asked for an unnecessary amount of detail. It seemed that they suspected the London Office was not really in control of their projects. As our main contact at BigBank said "There are challenges when reporting to <Head Office>. They expect detailed plans up front, and seem to believe that we are 'making it up as we go along"'. The London office tried to address these concerns by training Head Office staff in agile practices and the DSDM framework, mapping the agile process to the waterfall governance process, and using a range of different reporting styles and approaches to communication. However, concerns and challenges remained.

\subsubsection{Approach}

The aim of the case study was to address RQ2: How do practitioner challenges manifest themselves in an organisational setting? To this end, the investigation focused on exploring in depth the challenge being faced by BigBank, and understanding it in context.

Over the course of three months the research team regularly visited the company and collected data using interviews, group meetings and document review. Initially, the researchers were presented with a wide range of issues, which were gradually reviewed and refined. The focus was narrowed onto one project to scope the investigation (that we shall call FireFly). Firefly's aim was to migrate existing systems from a mainframe environment to a framework more commonly used within the domain. Data collection was undertaken when FireFly was in the last quarter of its planned timescale.

Table 2: List of job roles of Case Study interviewees

\begin{tabular}{|c|c|}
\hline Jobs roles interviewed & Interview questions \\
\hline $\begin{array}{l}\text { Manager of Project Management Office (PMO) (the } \\
\text { gatekeeper) }\end{array}$ & \multirow{10}{*}{$\begin{array}{l}\text { Semi-structured interview, based around the } \\
\text { following questions } \\
\text { 1. From your experience, what are the biggest } \\
\text { problems with reporting between London and } \\
\text { Head Office? } \\
\text { 2. What feedback do you get internally (in London)? } \\
\text { 3. What feedback do you get from Head Office } \\
\text { 4. What is your role in the process of reporting? } \\
\text { 5. Could you please tell us a little bit about your } \\
\text { 6. Hackground? } \\
\text { 7. Is there anything else you'd like to add? }\end{array}$} \\
\hline Head of Project Management Office (PMO) & \\
\hline Agile Coach & \\
\hline Visionary for FireFly & \\
\hline Project Manager for FireFly & \\
\hline Head of Regulatory Department & \\
\hline Deputy Head of Technology Department & \\
\hline $\begin{array}{l}\text { FireFly Sponsor, interface with senior } \\
\text { management in Head Office }\end{array}$ & \\
\hline $\begin{array}{l}\text { Head of Risk Regulation and Data Technology (a } \\
\text { developer role) }\end{array}$ & \\
\hline Head of Internal Audit & \\
\hline
\end{tabular}


The main data collection instrument was a set of semi-structured interviews, conducted during August 2013, with the group meetings and document review providing background and supporting information. Nine interviews were conducted with staff members who were identified by our contact at BigBank as being particularly impacted by the challenge initially identified. Interviews ranged between 20 minutes and an hour. The aim was to get a wide perspective on how the challenge manifested itself within the organisation, directly addressing RQ2. Initially, developers were not represented by any of the interviewees and one was added at our request. However his was the shortest interview as he was not impacted by the challenges we were investigating. The majority of communication with Head Office was conducted through project managers and the PMO, leaving developers to focus on their daily tasks. Protecting developers from this kind of challenge is a fundamental practice for agile software development. The ten roles represented by the interviewees and the questions asked during the interview are summarised in Table 2; Firefly's visionary and its project manager were interviewed together, at their request.

Four researchers were involved in data collection and analysis (three of the co-authors and one other researcher). The approach of affinity diagramming [27] was adopted for analysis (see Figure 4). Following this approach, each researcher individually extracted a list of sub-challenges from the data collected and a one-day analysis session was held in order to discuss and consolidate the issues raised. Related issues were collected into groups and the groups were described according to the underlying sub-challenge.

Figure 4: Affinity diagram of Case study sub-challenges (some labels are greyed out to avoid identification)

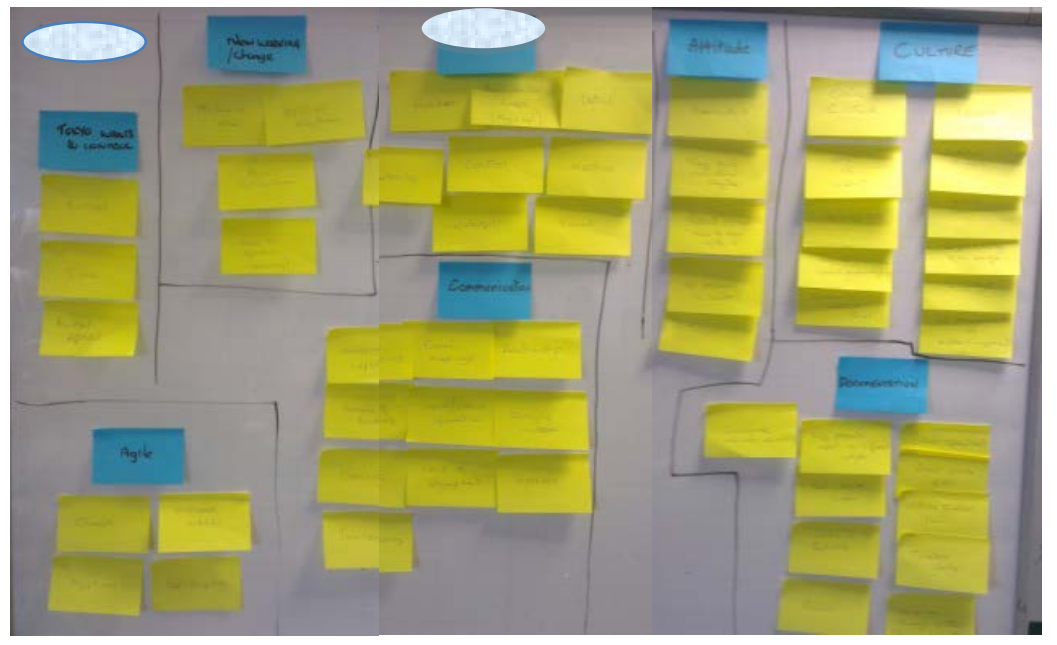

These sub-challenges were then considered in the context of the themes and subthemes identified through the Challenge Wall study. 


\subsubsection{Findings}

The four key sub-challenges that emerged through the affinity diagram analysis were:

1. How can different parts of the organisation communicate effectively when Head Office management values formal, written communication while the London Office agile teams value informal, verbal communication and minimal documentation

2. How to demonstrate control when Head Office management expects certainty of time, budget, and specifications from the beginning of the project but agile emphasises the delivery of fit-forpurpose, business value

3. How to overcome Head Office management perception of re-prioritisation and de-scoping as lack of control

4. How to respond to Head Office management who expect consistency in reporting right from the start even when the use of agile is still maturing.

In order to verify these sub-challenges and the main challenge characterisation, these findings were discussed with our collaborators at BigBank in December 2013. They welcomed the analysis and agreed with the findings. The fact that the original challenge evolved into many different sub-challenges was not a surprise to them, indicating that they recognised the complexity of the situation. In addition, it was clear that they perceived two parts to the first challenge: how to communicate effectively, and what needs to be reported. Building on this analysis and discussion, the main challenge widened its focus from only reporting, and became characterised as "Agile projects in a non-agile environment". According to the categories presented in Table 1, this is a subtheme of the Organisation theme, but the challenges were also linked to other themes and subthemes. To investigate this further, these subchallenges are considered in the context of the other themes and subthemes in Table 1.

The first challenge can be linked to the Organisational Culture subtheme of Culture. The Head Office wanted detailed, formal, hierarchical communication that was fully documented, but the London office preferred to use team-based, face-to-face, verbal communication to discuss detail and to produce minimal, 'just-enough' documentation for record-keeping. The documentation overhead demanded by Head Office took additional time for the London team. It undermined their agile approach and indicated a lack of trust. Head Office worked in a different language to the London office so some communication needed to be translated. This took time and introduced the potential for misunderstandings, which in turn sometimes led to additional queries for more information. Also, at Head Office employees rotated positions every two years, which involved not only a role change but also a Department change. This increased the challenge of establishing a mutual understanding of agile. 
The second challenge links to the Business Value subtheme, of the Value theme. As the Head Office environment did not fully accept and recognise the agile principles that the London office were using it was difficult to demonstrate progress and achievement of business value. From Head Office's point of view 'value' was associated with projects being on-time, on-budget and delivered according to specification. In contrast, the London office focused on delivering fit-for-purpose products that provided business value. The London office wanted to demonstrate control without retrofitting agile progress reports into templates designed for a waterfall environment, find the right level of detail for measuring and reporting progress and ensure that the information provided was interpreted correctly.

The third and fourth challenges link to the Organisation theme: the third to Management buy-in and understanding, and the fourth to Adoption. The London office was evolving their agile practice to suit their environment, and their approach was not yet mature. Head Office needed educating about the new approach. The Project Management Office (PMO) was still building up their agile knowledge base and introducing new processes. The reporting for different projects was not yet fully consistent and project report templates were still evolving. This compounded the perceived lack of full control and the likelihood that inconsistencies would be seen as problems. Because of lack of buy-in and understanding, Head Office considered some agile techniques such as reprioritisation and de-scoping as indicators a lack of control, rather than legitimate processes. Even small changes to a project's scope were considered to indicate a lack of control and hence failure to deliver.

The challenges found in the context of BigBank added rich detail to one of the subthemes in Table 1, but they also highlighted the interconnectedness of the themes identified from the Challenge Wall.

\subsubsection{Reliability and Limitations}

Credibility, transferability and dependability of the findings are related to the data collection approach and context, and the detailed descriptions provided of them. Limitations were the short period of time over which the study was conducted, and the fact that it was undertaken in one organisation. Many of the details described were specific to the organisation itself, as no other organisation would experience exactly the same set of conditions. The work was only done with staff at the London office and there was no access to Head Office staff.

Confirmability was achieved through four researchers working on and discussing the analysis of the data. The analysis was presented to and discussed with several members of BigBank towards the end of the study period to ensure credibility by research participants. 


\subsection{Online Survey}

An online Survey was developed to investigate further the Case Study findings. Specifically the aim was to understand whether others experienced the sub-challenges, and if there were other sub-challenges related to the main challenge of running agile projects in a non-agile environment.

\subsubsection{Approach}

The Survey asked for the respondent's role/job, which agile methods the respondent's organisation had adopted and the extent to which that organisation had adopted agile. The Survey went on to ask whether respondents had experienced the sub-challenges from the Case Study. These were modified from their previous form to better reflect the findings presented in section 3.2, and to be suitable for a survey format. The questions are reproduced in Table 3. Responses were elicited in the form of 'Yes', 'No', and 'Don't know'. The 'Don't know' option was included to capture situations in which respondents could not answer the question because their role meant that they did not have access to that information. The survey was aimed at respondents who were working in the context of "Agile projects in a non-agile environment", but not in exactly the same setting as BigBank. The Survey was developed iteratively and piloted by some staff from BigBank before being released online.

An invitation to complete the Survey was sent to more than 20 agile forums/message boards, LinkedIn and Meetup groups. The forums included yahoo on specific methods (Extreme Programming, Scrum Development, Agile Testing, Agile Project Management, Agile Usability and Lean Agile) and local and international forums (Agile Scotland, AgileNorth, Agile Staffordshire, Agile Wales, BCS Agile, Agile Alliance and Scrum Alliance); the LinkedIn groups were mostly of practitioners (Scrum Practitioners, Agile Coaching, DSDM, Agile Project Management, Agile Project Managers, Lean Agile Software Development Community, Agile .net Practitioners, Agile Coaching, Agile Managers Forum, Agile Project and Program Portfolio Management); the Meet-up groups reached were worldwide (Agile Sydney, Agile London Discussion Group, Agile Project Management, Agile Denver, The Chicago Agile Methodology Group, Agile Auckland, Agile-evangelists, Agile UX and Agile Testing). The Survey was conducted through SurveyMonkey over a period of nine months (June 2014 to February 2015).

Data was analysed using summary statistics and thematic analysis. Answers to closed questions were counted and collated as percentages. Answers to the open question were classified using the thematic classification scheme developed from the Challenge Wall data. Three researchers were involved in the data analysis.

\subsubsection{Findings}

There were 181 distinct responses to the Survey. The roles of respondents are shown in Figure 5. There was considerable variation in responses describing which agile methods were used. Scrum was used by $43 \%$ of respondents, a mix of Scrum and Kanban by 15\%, DSDM by 6\%, and a mix of Scrum and XP by 
$4 \%$. Of the other responses $14 \%$ mentioned using an ad hoc mix of methods including examples such as 'Scrum/Kanban/XP' and 'Scrum/SAFe'; 4\% used a single method including Kanban (2), XP (1), AWD (1), Lean (1), SAMBA (1), SAFe (1); and 13\% did not answer the question. Scrum was the most widely mentioned method, included in 69\% of respondents' answers. When asked the extent to which their organisation had adopted agile $76 \%$ stated that their organisation had only partially adopted agile, $14 \%$ stated their organisation had fully adopted agile and $10 \%$ stated their organisation had not adopted agile at all.

Figure 5: Job roles of survey respondents

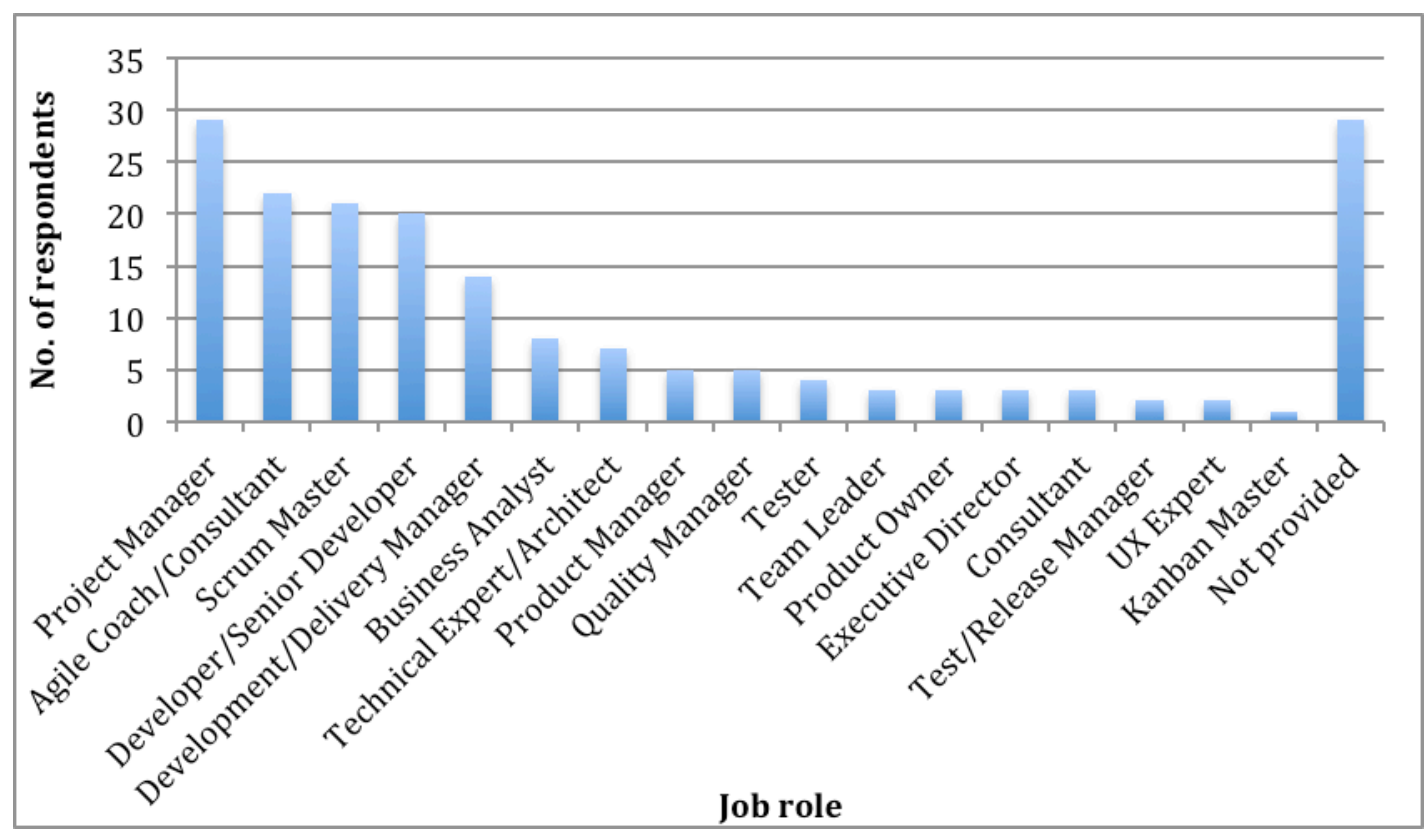

Summary statistics shown in the three right hand columns of Table 3 show that more than $50 \%$ of respondents had faced one or more of the "agile projects in a non-agile environment" sub-challenges identified through the Case Study, providing evidence that they are experienced in a range of settings.

Table 3: Have you experienced any of the following challenges while working with agile methods that you are currently using?

\begin{tabular}{|l|l|l|l|}
\hline & Yes & No & Don't know \\
\hline $\begin{array}{l}\text { Agile teams struggle to identify how to communicate their progress to } \\
\text { management }\end{array}$ & $51.53 \%$ & $41.10 \%$ & $7.36 \%$ \\
\hline $\begin{array}{l}\text { Agile teams struggle to identify what needs to be reported to } \\
\text { management }\end{array}$ & $53.61 \%$ & $36.75 \%$ & $9.64 \%$ \\
\hline $\begin{array}{l}\text { Management expects certainty of time, budget, and specifications from } \\
\text { the beginning of the project }\end{array}$ & $75.31 \%$ & $18.52 \%$ & $6.17 \%$ \\
\hline $\begin{array}{l}\text { Re-prioritisation and de-scoping is perceived by management as lack of } \\
\text { control }\end{array}$ & $50.62 \%$ & $38.27 \%$ & $11.11 \%$ \\
\hline $\begin{array}{l}\text { Management expects consistency in reporting right from the start even } \\
\text { when the teams are still in the process of transitioning to Agile }\end{array}$ & $53.99 \%$ & $33.13 \%$ & $12.88 \%$ \\
\hline Other (please specify) & & \\
\hline
\end{tabular}

Thirty-six responses were given to the 'Other (please specify)' part of the question. These identified 'them and us' issues, relating to process, mandatory procedures, micro-management, expectations, 
documentation, reporting, lack of experience and understanding of agile. Although these challenges were identified in the context of 'agile in a non-agile environment', they also can be classified within different themes and subthemes (see Table 4).

Table 4: Challenges identified in the context of 'agile in a non-agile environment' can be classified in different themes and subthemes

\begin{tabular}{|c|c|c|}
\hline Main Theme & Subthemes & Example Challenge \\
\hline $\begin{array}{l}\text { Claims and } \\
\text { Limitations }\end{array}$ & Misconceptions & $\begin{array}{l}\text { "Management uses the term "agile" to account for pushing the teams } \\
\text { harder, even towards constant overtime' }\end{array}$ \\
\hline \multirow[t]{5}{*}{ Organisation } & $\begin{array}{l}\text { Business \& IT } \\
\text { transformation }\end{array}$ & 'Setting proper expectations within other parts of the organization' \\
\hline & $\begin{array}{l}\text { Management buy- } \\
\text { in \& } \\
\text { understanding }\end{array}$ & $\begin{array}{l}\text { 'During agile adoption, management occasionally micromanages } \\
\text { until the Scrum teams have demonstrated a consistent delivery } \\
\text { process. Once teams hit their strides with consistent velocities, } \\
\text { Management tends to better understand and appreciate agile } \\
\text { philosophies' }\end{array}$ \\
\hline & $\begin{array}{l}\text { Agile in a non-agile } \\
\text { environment }\end{array}$ & $\begin{array}{l}\text { 'Communication requirements for agile team not met by } \\
\text { management/non-agile teams' }\end{array}$ \\
\hline & $\begin{array}{l}\text { Commitment/ } \\
\text { Engagement }\end{array}$ & 'Customers do not have agile experience' \\
\hline & Adoption & $\begin{array}{l}\text { 'Nobody knows agile except for me. One of my challenges is bringing } \\
\text { a large number of people up to speed not just with the 'rules' but also } \\
\text { the 'why' so that they can make pragmatic decisions' }\end{array}$ \\
\hline \multirow[t]{2}{*}{ Culture } & $\begin{array}{l}\text { Organisational } \\
\text { culture }\end{array}$ & $\begin{array}{l}\text { 'People are uncomfortable with the team members being } \\
\text { accountable for the outcomes and results' }\end{array}$ \\
\hline & Changing mindsets & $\begin{array}{l}\text { 'Parts of the team still want to work according to the Waterfall } \\
\text { process' }\end{array}$ \\
\hline \multirow[t]{2}{*}{ Sustainability } & $\begin{array}{l}\text { Process } \\
\text { improvement }\end{array}$ & 'Inter-sprint priority changes' \\
\hline & Contracts & 'We struggle to produce documentation that is part of the contract' \\
\hline
\end{tabular}

These findings illustrate how challenges are not only multi-faceted, but also complex and interrelated.

\subsubsection{Reliability and Limitations}

Credibility, transferability and dependability of the findings are related to the data collection approach and context, and the detailed descriptions provided of them. Limitations come from the convenience sampling approach used, the use of an online survey which made it impossible to check the credentials of respondents or the accuracy of the answers, and the lack of contextual information gathered about respondents. Confirmability was established by the analysis being undertaken by two researchers, however this could not be checked with participants as data was collected anonymously.

\section{Discussion}

The work presented in the previous section focussed on answering two research questions. This section returns to those research questions and discusses the implications of our findings. Section 4.1 summarises findings in answer to RQ1 and discusses how the landscape of challenges has changed over 
time by comparing our findings with previous research on agile practitioners' challenges. Section 4.2 summarises findings in answer to RQ2 and discusses why challenges are difficult to characterise by considering thematic perspectives and the systemic nature of challenges in organisational settings.

Section 4.3 compares the landscape of challenges identified in this paper with topics investigated in the research literature and discusses the implications for research that is relevant to practice. Section 4.4 discusses overall limitations and generalisability.

\subsection{What Challenges Do Agile Practitioners Face?}

In answer to RQ1, 'What challenges do agile practitioners face?' 27 subthemes and seven themes were identified. It was found that practitioners face a wide range of challenges, which can be expressed at different levels of granularity, many of which are multi-faceted and interlinked. The Challenge Wall data provided an opportunistic snapshot of the agile practitioner community's current concerns. But change is inevitable, and we now discuss how practitioner concerns have evolved over time by comparing the Challenge Wall data, collected from 2013 to 2015, with challenges collected at XP2010 and reported by Freudenberg and Sharp [18] (Table 5).

Table 5: Comparison of themes from this study with practitioners' top ten research questions from [18]

\begin{tabular}{|c|c|}
\hline $\begin{array}{l}\text { Freudenberg and Sharp top ten research questions } \\
\text { (numbers indicate ranking by size) }\end{array}$ & $\begin{array}{l}\text { Themes/Subthemes } \\
\text { (numbers indicate ranking by size) }\end{array}$ \\
\hline 1. Agile and large projects & 6. Scaling \\
\hline 2. What factors can break self-organization? & 3. Culture/Organisational culture \\
\hline $\begin{array}{l}\text { 3. Do teams really need to always be collocated to } \\
\text { collaborate effectively? }\end{array}$ & 3. Culture/Distributed teams \\
\hline $\begin{array}{l}\text { 4. Architecture and agile-how much design is enough } \\
\text { for different classes of problem? }\end{array}$ & 6. Scaling/Large projects \\
\hline $\begin{array}{l}\text { 5. Hard facts on costs of distribution (in } \$, £, € \text { and so } \\
\text { on) }\end{array}$ & 3. Culture/Distributed teams \\
\hline $\begin{array}{l}\text { 6. The correlation between release length and success } \\
\text { rate }\end{array}$ & $\begin{array}{l}\text { 1. Claims and Limitations/Shortcomings } \\
\text { Sustainability/Process Improvement }\end{array}$ \\
\hline 7. What metrics can we use with minimal side effects? & 7. Value/Measurement \\
\hline $\begin{array}{l}\text { 8. Distributed agile and trust-what happens around } \\
8-12 \text { weeks? }\end{array}$ & 3. Culture/Distributed teams \\
\hline $\begin{array}{l}\text { 9. Statistics and data about how much money/time is } \\
\text { saved by agile }\end{array}$ & $\begin{array}{l}\text { (Time mentioned in several challenges from } \\
\text { different themes) }\end{array}$ \\
\hline $\begin{array}{l}\text { 10. Sociological studies-what were the personalities } \\
\text { in successful/failed agile teams? }\end{array}$ & 4. Teams/ Finding good people \\
\hline
\end{tabular}

Some research questions from 2010 are still a challenge today although they have changed emphasis, towards organisational concerns and away from internal agile team matters. For example, scaling challenges now relate to organisations, rather than large projects:

'How do you scale up to a large project over many months or even years?';

'Scaling due to complexity (rather than large projects)'; and

'Scaling across a large enterprise/companies.' 
The challenge of metrics is now less about side effects and more about what management wants and how to measure value:

'Agile is about measuring value, but management want efficiency, defect metrics etc. How to demonstrate team is efficient and improving efficiency?'

'Lack of focus on business value (and identifying what it means).'

Similar concerns were found in BigBank's first sub-challenge about communicating effectively when Head Office management valued different kinds of communication than the London Office.

Co-location of teams is still an issue (under the Culture theme) but trust has emerged as a key concern.

The research questions relating to specificities of agile practice such as: 'Architecture and agile-how much design is enough for different classes of problem?'; and 'The correlation between release length and success rate' seem to have less importance now. The current challenges around agile practices are not 'how to' challenges but are misconceptions and shortcomings. For example:

'It's hard to make it work with clunky legacy systems'

Or from the Survey findings:

'Teams and managers breaking out of Scrum methodology \& framework to reduce what they perceive as "framework" waste'

The lack of 'how to' challenges suggests a move away from understanding agile towards a wider concern of sustainability within more or less hostile environments. The high number of agile challenges in the Organisation theme and of organisation-related ones in other themes reinforces this point.

\subsection{How Do Practitioner Challenges Manifest Themselves in Organisational Settings?}

In answer to RQ2, 'How do practitioner challenges manifest themselves in an organisational setting?', the Case Study revealed a web of detailed, inter-linked sub-challenges. The Survey confirmed that these were experienced in different contexts by over $50 \%$ of respondents. Even when a specific challenge area was the focus, other interlinked challenges were uncovered through the study, and we found those challenges could be categorised under other challenge themes.

The challenge analysis shows that some challenges relate to more than one thematic category, and if viewed from a different perspective or investigated in more depth could be categorised differently. For example, BigBank's main challenge was an example of the subtheme 'agile projects in a non-agile environment' in the Organisation theme. However, when this challenge was investigated in depth four sub-challenges were identified. As discussed at the beginning of section 3.2.3 these sub-challenges could be linked to four specific sub-themes in the Culture, Value and Organisation themes.

We suggest that the seven themes are more useful if they are seen as 'perspectives' or 'lenses'. These perspectives are not distinct boxes into which challenges can be fitted, but standpoints or perspectives 
from which the challenges can be viewed. The Organisation theme looks at challenges from the standpoint of organisational structures and processes whereas the Team theme uses the perspective of groups of individuals. Culture uses the perspective of the ethos and rules that are in play within working environments. Sustainability uses the standpoint of longevity and time, Scaling uses size and Value uses the perspective of benefit or worth. Claims and Limitations uses the perspective of how agile itself is perceived and how those perceptions themselves create challenges. Seen in this way some agile challenges are multi-dimensional problems that are experienced simultaneously as business, organisational, social and adaptation problems.

The inter-related themes identified in this study reflect the complex and multi-faceted environments in which software is developed. There is a long tradition of applying systems theory to organisations [28, 29]. Also, several authors have used a Complex Adaptive Systems view to explain agile methods in organisational contexts [30-33]. A system is an interconnected set of elements forming a whole that has properties belonging to the whole. A complex adaptive system uses transformative feedback loops to enable continuous improvement, has emergent and potentially unpredictable behaviour, distributed rather than centralised control; a shallow rather than a deep structure; and is enhanced by growth and evolution [30]. From this viewpoint an agile adoption should transform the whole organisation [34]. Some practitioners' challenges, therefore, are multi-dimensional and either the challenges themselves, or the changes needed to address them, are disruptive to the organisational system within which they sit.

On the one hand this complexity is not surprising, but on the other it provides a salutary lesson for researchers wishing to investigate practitioner challenges. There is a tension between taking account of this complexity and developing specific research questions. It is often the case that resource and funding constraints dictate a tight research focus, but this is at odds with the landscape this work has uncovered. Different kinds of empirical study are used by researchers, which can be broadly categorised as in vivo, in vitro and in silico [35]. The findings here particularly support the need for in vivo case studies, the use of systems approaches to research such as action research [36], soft systems methodology [29] and systems dynamics [37], and recognition that a simplistic view of practitioner challenges is not helpful for practitioners.

\subsection{Which Challenges Are Being Addressed by Research?}

Findings show that practitioners face a wide range of challenges that change over time, are complex and interlinked. We now look at which challenges are being addressed by research. We compare themes and subthemes from this study with areas identified in Dybå and Dingsøyr's 2008 systematic literature review [10] (Table 6). We discuss findings from this study in the light of a more recent systematic literature review, in 2014, by Chuang et al [13] that highlights what research has been carried out on 
specific subthemes . Also relevant, is the investigation by van Waardenburg and van Vliet [21] of agile within a plan-driven environment, omitted by Chuang et al [13].

Table 6: Comparison of themes and subthemes from this study with Dybå and Dingsøyr's topics [10]*

\begin{tabular}{lll}
\hline Dybå and Dingsøyr topics & $\begin{array}{l}\text { Themes from this } \\
\text { study }\end{array}$ & Subthemes from this study \\
\hline Introduction and adoption & & Adoption \\
\hline Introduction and adoption & Organisation & (Not mentioned in our challenge list) \\
\hline Development process & Knowledge sharing \\
\hline $\begin{array}{l}\text { Knowledge and project } \\
\text { management }\end{array}$ & Sustainability & \\
\hline Human and social factors & & Organisational culture \\
\hline Organisational culture & Culture & Team practices \\
\hline Collaborative work & Teams & Finding good people \\
\hline Team characteristics & Teams & Commitment/engagement \\
\hline Perceptions of agile & & Individual motivation \\
\hline Customer perceptions & Organisation & Adoption \\
\hline Developer perceptions & Teams & (Not mentioned in our challenge list) \\
\hline Student perceptions & Organisation & \\
\hline Comparative studies & & Management buy-in and \\
\hline Project management & & understanding \\
& Organisation & Process improvement \\
\hline Productivity & Sustainability & Process Improvement \\
\hline Product quality & Sustainability & (Not mentioned in our challenge list) \\
\hline Work practices and job & Teams & Team practices \\
\hline Dybå and Dingsøyr identify four topic groups and 13 topics, which are mapped to four themes and nine subthemes from this study.
\end{tabular}

Organisation, Sustainability, Culture and Teams are themes that have been subject to research interest for some time. For example the topic groupings identified in Dybå and Dingsøyr's systematic review [10] are reflected in these four themes from our challenge set. Also, van Waardenburg and van Vliet [21] identify 'lack of business involvement' as one of their two categories of challenges (the other being 'increased landscape complexity') which maps to our subtheme Management buy-in and understanding. Gandomani et al [20] identify 'organisation and management related' as one their challenge themes; this includes challenges that we have classified under Organisation (e.g. 'transforming [...] from "command and control" to "leadership and collaboration'”' that we classified under Business and IT transformation) but also under Culture ('Changing mindset of people and their organisational culture' under Changing mindsets). Conboy et al [22] focus on people-related challenges some of which relate directly to subthemes; for example, 'Developer fear caused by transparency of skills deficiencies' relates to Organisation; 'lack of agile specific recruitment policies and suitably trained IT graduates' relates to Finding the right people (Teams), 'Lack of developer motivation to use agile methods' relates to Individual motivation (Teams). However some subthemes within three of these four main themes (Organisation, Sustainability, and Teams), such as Business and IT transformation, Fear, Contracts, Documentation and Leadership, do not seem very evident in the literature searches we have conducted for our industrial partners. This would, however, need to be 
confirmed by a more up-to-date systematic literature review. The need for business as well as IT transformation, was of particular concern in the Challenge Wall data, with 11 challenge cards identifying this topic. Examples of challenges identified included:

'Its take up outside of the delivery function. That it is has been coined by IT for IT without the business guys. Which organisational changes are triggered by IT without anybody noticing/caring/managing those changes?'; and

'That everyone seems to think that it starts and stops in software development. How other disciplines blend in is a big challenge'.

A similar example from the Survey is:

'Senior management does not communicate detail of the Agile transformation to middle management.'

BigBank's third challenge ('How to overcome Head Office management perception of re-prioritisation and de-scoping as lack of control') also refers to the need for business transformation.

Scaling is also a topic that has been written about and discussed by practitioners $[38,39]$. Chuang et al [13] reference seven papers on scaling, including large or complex projects (searching on 'scale', 'large', 'complex') and none on governance (searching on 'governance', 'PMO'). Dingsøyr and Moe reported from an XP2013 Workshop at which research challenges in large-scale agile development were discussed, that there were few research studies on the topic [19]. A recent systematic literature review on agile governance, identified a small but growing research base [40].

The two themes Value, and Claims and Limitations identified in our challenge set are generally less commonly reported in the empirical research literature, although some of the associated subthemes are more researched. In the references in Chuang et al [13] we found no papers on the topic of business value (searching on 'value'); eight discussing measurement ('metrics', 'measurement'); and none on claims or limitations ('misconception', 'shortcoming', 'fail', 'hype', 'lack', 'claim', 'limitation').

Challenge Wall participants identified 46 challenges on the theme of Claims and Limitations. Comments indicate a certain amount of frustration, but range over a number of topics, including:

'Religious approach';

'Everyone wants to reinvent it';

'Throwing away some of the old useful ideas'; and

'The lack of a project management framework for coordinating multiple teams and or work.' And from the Survey findings: 
'Lack of understanding the agile philosophy by Top Management, while strong from development team'

While there is some literature about the concept of agility $[6,41]$, there is very little about misconceptions, hype and failure. Agile hype is discussed by Janes and Succi [42] who suggest agile has followed the Gartner Hype Cycle, and is stuck in the 'Trough of Disillusionment' as a result of what they call the 'guru phenomenon'. In a grounded theory study of agile practitioners Hoda et al [43] identify agile hype and scepticism as factors that negatively affected customer involvement in agile projects. There are some discussions in the consultant literature [44], however we could find no empirical research that specifically focussed on investigating this topic.

There is very little research into agile failure, another subtheme of Claims and Limitations. McAvoy and Butler [45] report the failure of a team to adopt an agile method, identifying ineffective decision-making and actions, which occurred as a result of the team's desire to become more cohesive, as one of the key drivers of the failure. This is a gap, and has been mentioned by other researchers [13]. It is somewhat surprising as anecdotally it is not uncommon to hear stories of failure and organisational abandonment of agile.

We also compared our findings with the research areas Dingsøyr et al established in their 2008 preliminary roadmap paper [9] as goals for research achievements by 2015. They indicate some areas for priority in research: maturity, coverage, understanding and impact. They assess that research was having little impact on everyday practice in industry and suggest that "increased application of research methods like action research [36] can be helpful ensuring the relevance, and help provide a larger body of knowledge that can lead to a broader impact on industry."

Research in the area has grown significantly [13], action research is being used [46, 47] and research may be getting more relevant and is definitely increasing the body of knowledge. However, some perspectives from our challenge list are:

'That there is no academic research supporting the claimed success'; and,

'It is isolated from many fields, e.g., a good research could be about bringing information visualisation theory and methods into agile project management in a systematic way.' This suggests that even if research has been done, the gap between research and what industry wants to know has not yet been bridged.

\subsection{Limitations}

This paper is an extension of an earlier publication [7]. Additional empirical data from the case study adds depth of analysis and the survey extends and validates the previous findings. Overall limitations 
for the generalisability of the research are related to the number and type of practitioners accessed and the venues at which data was collected. In all three studies the focus of data collection was not specifically at the level of the development team. Managers of various types are better represented than developers, analysts or testers in the Challenge Wall and Survey data and the challenge investigated in the Case Study did not impact on developers. Much of the work was undertaken in the UK, with a focus on the DSDM community. It is therefore likely that the data collected reflects manager-level perspectives more closely than developer perspectives, and because of this some concerns may not be represented.

This paper presents a snapshot of Agile challenges faced by the industry at one point in time. Further research with a broader and larger set of participants and additional methods such as workshops, round-table discussions, and focus groups would strengthen the findings.

\section{Conclusions}

If research is to have real impact in the practitioner community, researchers need to understand and address the challenges that this community faces. The research questions addressed in this paper help to inform this endeavour by mapping the landscape of current practitioner challenges, identifying the persistent yet evolving nature of challenges and illustrating the complexity that emerges when challenges are studied in an organizational context. Specifically, this work shows that:

1. The landscape of practitioner challenges is complex and the challenges are interlinked. Attempts by researchers to address these challenges need to recognise this and to treat the challenges in context rather than in isolation.

2. Some challenge areas have persisted for many years, and are just hard to address successfully. For example, identifying and measuring agile value, and understanding cultural change are highly contextual and complex. These challenge areas will continue to benefit from further research because it needs to keep abreast of cultural change.

3. Some challenge areas appear to have persisted for many years, but further analysis shows that their focus has changed, specifically towards organisational concerns. As agile is adopted outside the IT function some agile challenges become systemic. Further research and work with relevant disciplines needs to increase.

4. Practitioners are less concerned about adopting agile and more concerned about sustaining agile. The sustainability of agile has not been widely researched.

5. Other challenge areas have also not been widely researched, specifically governance, business engagement and transformation, failure, and the impact of claims and limitations. Future research would be beneficial in some of these areas, but it is not the answer to all of them as some would best 
be addressed by further or different education and training - e.g. those challenges classified as misconceptions and hype.

6. Some challenge areas appear in the current landscape of challenges but have also been the subject of research studies, such as business and IT transformation, changing mindsets, finding the right people and scaling. This implies that the research being done is not having the expected impact. This suggests further dissemination of the results, or re-packaging of the results to encourage practitioner implementation.

Overall, the picture is one of a complex, multi-faceted and constantly changing landscape of practitioner challenges. In the last five years (between 2010 and 2015) concerns of sustainability and organizational context have grown, and these would benefit from both further research and improvements in knowledge transfer. Furthermore, given the complex nature of the challenge landscape, engaged Case Study research will continue to be of paramount importance.

\section{Acknowledgements}

We would like to thank the conference attendees, survey respondents, our collaborators at BigBank, and our funders: the Dynamic Systems Development Method (DSDM) Consortium, the Open University and the University of Central Lancashire.

\section{References}

[1] E. Papatheocharous, A.S. Andreou: Empirical Evidence and State of Practice of Software Agile Teams, Journal of Software: Evolution and Process, 26 855-866 (2014)

[2] N.B. Moe, T. Dingsøyr, T. Dyba: Understanding Self-organising Teams in Agile Software Development, in: 19th Australian Conference on Software Engineering, IEEE, (2008)

[3] N.B. Moe, T. Dingsøyr, T. Dyba: A Teamwork Model for Understanding an Agile Team: A Case Study of a Scrum Project, Information and Software Technology, 52 480-491 (2010)

[4] M. Laanti, J. Similä, P. Abrahamsson: Definitions of Agile Software Development and Agility, in: F. McCaffery, R. O’Connor, R. Messnarz (Eds.) Systems, Software and Services Process Improvement, Springer Berlin Heidelberg, pp. 247-258 (2013)

[5] Agile Manifesto: http://www.agilemanifesto.org, in, (2001)

[6] K. Lyytinen, G.M. Rose: Information System Development Agility as Organisational Learning, European Journal of Information Systems, 15 183-199 (2006) 
[7] P. Gregory, L. Barroca, K.J. Taylor, D. Salah, H. Sharp: Agile Challenges in Practice: A Thematic Analysis, in: C. Lassenius, T. Dingsøyr, M. Paasivaara (Eds.) Proceedings of the 16th International Conference XP 2015, Springer, Helsinki, Finland, LNBIP 212, pp. 64-80 (2015)

[8] P. Abrahamsson, J. Warsta, M.T. Siponen, J. Ronkainen: New Directions on Agile Methods: A Comparative Analysis, in: International Conference on Software Engineering, IEEE, Portland, Oregon USA, (2003)

[9] T. Dingsøyr, T. Dybå, P. Abrahamsson: A Preliminary Roadmap for Empirical Research on Agile Software Development, in: Proceedings of AGILE, IEEE, Toronto, Canada, pp. 83-94 (2008) [10] T. Dybå, T. Dingsøyr: Empirical Studies of Agile Software Development: A Systematic Review, Information and Software Technology, 50 833-859 (2008)

[11] P. Abrahamsson, K. Conboy, X. Wang: "Lots Done, More To Do": The Current State of Agile Systems Development Research, European Journal of Information Systems, 18 281-284 (2009)

[12] T. Dingsøyr, S. Nerur, V. Balijepally, N.B. Moe: A Decade of Agile Methodologies: Towards Explaining Agile Software Development, The Journal of Systems and Software, 82 1213-1221 (2012)

[13] S. Chuang, T. Luor, H. Lu: Assessment of Institutions, Scholars, and Contributions on Agile Software Development (2001-2012), Journal of Systems and Software, 93 84-101 (2014)

[14] S. Jalili, C. Wohlin: Global Software Engineering and Agile Practices: A Systematic Review, Journal of Software Maintenance and Evolution: Research and Practice, (2011)

[15] Y.I. Alzoubi, A.Q. Gill: Agile Global Software Development Communication Challenges: A Systematic Review, in: PACIS14, (2014)

[16] J. Ferreira: User Experience Design and Agile Development: Integration as an On-going Achievement in Practice, in, PhD Thesis, Open University, (2011)

[17] K. Dwan, D.G. Altman, J.A. Arnaiz, J. Bloom, A. Chan, E. Cronin, E. Decullier, P.J. Easterbrook, E. Von Elm, C. Gamble, D. Ghersi, J.P.A. Ioannidis, J. Simes, P.R. Williamson: Systematic Review of the Empirical Evidence of Study Publication Bias and Outcome Reporting Bias, PloS one, 3 e3081 (2008)

[18] S. Freudenberg, H. Sharp: The Top 10 Burning Research Questions from Practitioners, IEEE Software, September/October 8-9 (2010)

[19] T. Dingsøyr, N.B. Moe: Research Challenges in Large-Scale Agile Software Development, ACM SIGSOFT Software Engineering Notes, 38 38-39 (2013)

[20] T.J. Gandomani, H. Zulzalil, A.A.A. Ghani, A.B.M. Sultan, M.Z. Nafchi: Obstacles in Moving to Agile Software Development Methods: At a Glance., Journal of Computer Science, 9 620-625 (2013) [21] G. van Waardenburg, H. van Vliet: When Agile Meets the Enterprise, Information and Software Technology, 55 2154-2171 (2013)

[22] K. Conboy, S. Coyle, X. Wang, M. Pikkarainen: People over Processes: Key Challenges in Agile Development, IEEE Software, 28 48-57 (2011) 
[23] V. Braun, V. Clarke: Using Thematic Analysis in Psychology, Qualitative Research in Psychology, 3 77-101 (2006)

[24] Y.S. Lincoln, E.G. Guba: Naturalistic Inquiry, Sage, (1985)

[25] A.K. Shenton: Strategies for Ensuring Trustworthiness in Qualitative Research Projects, Education for Information, 22 63-75 (2004)

[26] P. Runeson, M. Höst: Guidelines for Conducting and Reporting Case Study Research in Software Engineering, Empirical Software Engineering, 14 131-164 (2009)

[27] H. Beyer, K. Holtzblatt: Contextual Design: Defining Customer-Centered Systems, Elsevier, (1997)

[28] F.E. Kast, J.E. Rosenzweig: General Systems Theory: Applications for Organization and Management, Academy of management journal, 15 447-465 (1972)

[29] P. Checkland, J. Scholes: Soft Systems Methodology: A 30-year Retrospective, John Wiley \& Sons, (1999)

[30] P. Meso, R. Jain: Agile Software Development: Adaptive Systems Principles and Best Practices, Information Systems Management, 19-30 (2006)

[31] R. Vidgen, X. Wang: Coevolving Systems and the Organization of Agile Software Development, Information Systems Research, 20 355-376 (2009)

[32] S. Augustine, B. Payne, F. Sencindiver, S. Woodcock: Agile Project Management: Steering from the Edges, Communications of the ACM, 48 85-89 (2005)

[33] S. Nerur, R. Mahapatra, G. Mangalaraj: Challenges of Migrating to Agile Methodologies, Communications of the ACM, 48 73-78 (2005)

[34] M. Laanti, O. Salo, P. Abrahamsson: Agile Methods Rapidly Replacing Traditional Methods at Nokia: A Survey of Opinions on Agile Transformation, Information and Software Technology, 53 276-290 (2011)

[35] V.R. Basili: The Role of Controlled Experiments in Software Engineering Research, in: Empirical Software Engineering issues. Critical Assessment and Future Directions, Springer, Berlin, pp. 33-37 (2007)

[36] D. Avison, F. Lau, M.D. Myers, P.A. Nielsen: Action Research, Communications of the ACM, 1 94-97

[37] D.C. Lane, R. Oliva: The Greater Whole: Towards a Synthesis of System Dynamics and Soft Systems Methodology, European Journal of Operational Research, 107 214-235 (1998)

[38] J. Eckstein: Agile Software Development in the Large: Diving into the Deep, Dorset House Publishing, New York, (2004)

[39] J. Sutherland: Agile Can Scale: Inventing and Reinventing SCRUM in Five Companies, Cutter IT Journal, 14 5-11 (2001) 
[40] A.J.H.d.O. Luna, P. Kuruchten, M.L.G.d.E. Pedrosa, H.R. de Almeida Neto, H.P. de Moura: State of the Art of Agile Governance: A Systematic Review, International Journal of Computer Science \& information Technology, 6 121-141 (2014)

[41] K. Conboy: Agility from First Principles: Reconstructing the Concept of Agility in Information Systems Development, Information Systems Research, 20 329-354 (2009)

[42] A. Janes, G. Succi: The Darker Side of Agile Software Development, in: International Symposium on New Ideas, New Paradigms, and Reflections on Programming and Software, ACM, pp. 215-228 (2012) [43] R. Hoda, J. Noble, S. Marshall: The Impact of Inadequate Customer Collaboration on Self-Organising Agile Teams, Information and Software Technology, 53 521-534 (2011)

[44] J. Brousseau: Beyond the Hype of a New Approach, in: Cutter IT Journal, Cutter Consortium, pp. 2530 (2004)

[45] J. McAvoy, T. Butler: A Failure to Learn in a Software Development Team: The Unsuccessful Introduction of an Agile Method, in: W. Wojtkowski, G. Wojtkowski, M. Lang, K. Conboy, C. Barry (Eds.) Information Systems Development: Challenges in Practice, Theory and Education, Springer US, (2010) [46] P. Svejvig, A.D.F. Nielsen: The Dilemma of High Level Planning in Distributed Agile Software Projects: An Action Research Study in a Danish Bank., in: Agility Across Time and Space, Springer, pp. 171-182 (2010)

[47] L. Barroca, H. Sharp, D. Salah, K.J. Taylor, P. Gregory: Bridging the Gap Between Research and Agile Practice: An Evolutionary Model, International Journal of System Assurance Engineering and Management, 1-12 (2015) 